\title{
Opening Doors with Informal Science: Exposure and Access for Our Underserved Students
}

\author{
LESLIE S. JONES \\ Department of Biology, University of Northern Iowa, Cedar Falls, IA 50614-0421, USA; \\ e-mail: leslie.jones@uni.edu
}

Received 30 October 1996; accepted 15 May 1997

\begin{abstract}
As it has become apparent that there is a need to broaden the emphasis of science education and ensure that every student achieves a level of science literacy, science educators face the challenge of addressing new audiences that are not always well-served by traditional presentations of scientific material. The challenge of presenting agricultural science to urban African American students typifies a scenario that necessitates devising new approaches to teach people who were previously overlooked or even ignored by the scientific community. The Young Scholars Program at The Ohio State University (OSU) is a 6-year precollegiate intervention program designed to prepare academically talented, economically disadvantaged minority students for college education. This novel outreach program was developed with the primary intention of enhancing the educational background of all of these young people by increasing their agricultural literacy. A secondary goal lay in the hope that some of these students might be enticed to consider the possibility of collegiate study in agricultural fields, thus infusing some much needed racial/ethnic diversity into the College of Food, Agriculture, and Environmental Sciences' student population. To address anticipated disinterest on the part of the students, an informal approach designed to emphasize the relevance, breadth, technical sophistication, and aesthetic components of agricultural science was devised. Students were taken on educational field trips to various college departments as part of an academic program during summer visits to the OSU. Efforts were made to use nontraditional (all women and men of color) scientists as many of the presenters to break down the stereotypical notion that only white males do science. Deliberate educational strategies were employed to enhance the educative aspects of the visits. A science/writing exercise served the dual purpose of prompting student reflection as well as being the evaluation instrument to assess the efficacy of the program. The success of this effort to reshape the traditional presentation of agriculture was demonstrated in much of the testimony of the students as well as the verbal and written observations of the adults involved. The demonstrable success of this project documents the possibility of an initiative addressing the dual challenge of opening the doors of science while simultaneously cultivating the interest of historically underrepresented people in nontraditional subject areas. This research further supports the idea that an informal approach to science education can be a particularly effective intervention strategy for reaching out to underserved students. (c) 1997 John Wiley \& Sons, Inc. Sci Ed 81:663-677, 1997.
\end{abstract}

Correspondence to: L. S. Jones 


\section{RATIONALE}

Despite the contemporary focus on multiculturalism in our society, particularly in education, there is not nearly enough practical discussion of ways classroom settings can be transformed so that the learning experience is inclusive. If the effort to respect and honor the social reality and experiences of groups in this society who are nonwhite is to be reflected in a pedagogical process, then as teachers - on all levels, from elementary to university settings - we must acknowledge that our styles of teaching may need to change. (hooks, 1994, p. 35)

There is growing recognition that one constituent of the science education reform process must be sustained effort toward making the study of science accessible to more people. As we look for ways to encourage children from various cultural backgrounds to see the personal relevance of science, it is clear that traditional formal instruction should not be the only approach. The informal setting holds tremendous possibility as a mechanism for enhancing the appeal of science lessons. The novelty of new environments can stimulate curiosity and exploratory behaviors (Falk, Martin, \& Balling, 1978). There are multidimensional opportunities for learning which cater to the tastes and preferences of a greater number of the individual students. The flexibility and lack of rigidity leaves students room to investigate and attend to what interests them. For students who cope with the social incongruity of an educational system that is based on a second language or an unfamiliar value system, it can provide the freedom to learn in more comfortable ways as suggested by Lee, Fradd, and Sutman (1995).

The Young Scholars Program of The Ohio State University places a large group of academically talented, urban, racial/ethnic minority students on the campus of a large, predominantly white, land-grant university. The presence of these students, who would normally have little or no exposure to agricultural science, provided the incentive to undertake this action research project involving an informal approach to science education. Previous efforts to expose other students from the Young Scholars Program to the agricultural sciences through more formal visits and even hands-on laboratory activity sessions had been discouraging and unsuccessful due to apparent student disinterest. The current initiative was conceived as an attempt to recontextualize their experience by dramatically changing the nature of the visits. The innovation was designed primarily to address their limited agricultural literacy with the additional possibility that it might also work to recruit some of these nontraditional students to consider collegiate study in the College of Food, Agricultural, and Environmental Sciences.

The goal of the project was to create an educational experience that these students might find personally relevant. The presumption was that if they could see the connection between agriculture and their own lives, they might be more interested in the scientific aspects of the presentations. Beginning with our understanding of the participants' existing knowledge base and likely negative perceptions of agriculture, these activities were designed for the target audience. Rather than emphasize the usually taught aspects of agricultural science that are known to appeal to white children from rural backgrounds, we exposed these young people to other aspects of our field that we hoped would be interesting, culturally pertinent, and as aesthetically pleasing as possible. The objective of the program was to provide a setting in which Ohio State agricultural scientists could effectively share their knowledge and enthusiasm in a manner that would be likely to reach the students. Several parts of the program, such as the orientation session run by African American members of the college and the use of study questions that prompted students to verbally communicate with the presenters, were specifically chosen to bridge areas of known cultural dissonance. Our goal of enhancing their agricultural literacy depended on capturing their attention and helping them see the role of agriculture in their own lives. 


\section{CONTEXT}

In the second half of this century, as science education became more focused on serving as a critical "pipeline" channeling students toward scientific and technical careers, it became less efficient at providing other students with so much as a minimal level of scientific competence. In our elementary schools, science is often missing from the curriculum or presented in such a way that it squelches children's innate curiosity about natural phenomena. The preprofessional orientation of secondary science education has fostered both an impression of foreboding complexity and an impersonal pedagogical style that continue to be deterrents to students who are not devoted to a science career path. In what has come to be recognized as a national crisis of science literacy, it is also clear that certain populations of students are particularly unlikely to elect to participate in the study of science. Recent attempts to democratize science education and meet the needs of a broader section of the general populace have met with only limited success (National Science Foundation, 1994). Progress toward improving racial/ethnic diversity in the sciences has not paralleled even the modest gains that have been seen from efforts to include greater numbers of women.

Students' science interests differ according to their racial/ethnic background (Catsambis, 1995), and certain disciplines have been more successful than others at attracting nontraditional students. According to statistics from the National Science Foundation (1994), agriculture grants only $6.7 \%$ of all bachelor's degrees to people of color, whereas $21 \%$ are earned by nonwhites in the other life sciences. Widespread perceptions that agriculture is nothing more than farming ignore the tremendously productive basic science research and variety of other technical opportunities that are available. Additionally, the impressions that a career in agriculture means going "back to the fields" is a particular deterrent to many African American students. Whether it conjures up recollections of sharecropping or slavery, neither is an appealing prospect to young African American people.

\section{EDUCATIONAL INNOVATION}

\section{The Young Scholars Program}

In a statewide effort to address the serious problem of relatively few African American, Latino-Hispanic American, Appalachian, and Native American students successfully completing a college education, The Ohio State University created the Young Scholars Program in 1988 (OSUOMAYSP, 1995a). Academically-talented, economically-disadvantaged students who will be the first generation of college graduates in their immediate family are selected for the program in the sixth grade. Nine urban school districts are involved: Akron, Canton, Cincinnati, Cleveland, Columbus, Dayton, Lorain, Toledo, and Youngstown. Over $80 \%$ of the students are African American. Female and male students are admitted in equal numbers, but attrition is greater for male students and their representation drops to under $40 \%$ of the collegiate students (OSUOMAYSP, 1995b). The 6-year enrichment program involves a supervised college preparatory program in their own schools and annual visits to the university for an intensive summer institute. Young scholars who successfully complete the program and graduate from high school with a cumulative grade point average of 3.0 or greater are admitted to the university and provided with appropriate funding.

Career exploration experiences in various scholastic programs are a major component of the summer institute for the scholars. The students spend mornings in formal classes in traditional subject areas, but afternoons are dedicated to learning more about collegiate academic possibilities with an emphasis on eventual vocational prospects. This focus on the significance of collegiate study to their eventual career possibilities addresses one of the most common 
criticisms of career education, which is to center on the distant endpoint without showing students what their training will involve (Krepel \& DuVall, 1981). The young scholars have the opportunity to visit academic areas within the university in the hope that they will see the connection between their choice of collegiate study and subsequent professional employment possibilities. Efforts had been made to provide engaging laboratory science career exploration experiences in various departments within the College of Food, Agricultural, and Environmental Sciences for several years. These were generally modified college science labs or demonstrations that seemed to have very little appeal to any of the students. Unfortunately, contact was only made with small numbers of students who seemed to have little interest in being there. Their negative reaction made it quite apparent that they considered the presentations tedious and unnecessary. The discouragement of the participating agricultural scientists is reflected in comments made on evaluations such as those made by the following two scientists:

. . . we felt the students had a lack of interest for hands-on experience we had to offer in our lab.

I opted not to participate [again] because the scholars didn't show much interest in the labs which had been set up for them.

Thus, with the dwindling willingness on the part of our staff to provide laboratory experiences for the Young Scholars Program, we needed to develop an approach that was more enticing for the students and rewarding for the scientists who would be involved.

Responsive education must attend to the particular needs of modern society. As Arkinstall (1977) suggests, it is possible to extend children's horizons and improve their education by moving beyond the comfortable confines of the traditional curriculum and the domestic indoor experience. The multisensory environment of the setting in the College of Agriculture was well-suited to stimulate what Dierking and Falk (1994) refer to as the aesthetic and kinesthetic experiences possible in informal settings. If formal presentations were so unsuccessful with these students, there was some hope that the nature of the field trip experience would generate enthusiasm and interest. Hammerman and Hammerman (1973) discuss going outside the classroom setting to enrich, vitalize, and complement content areas of the curriculum by means of first-hand observation. They advocate looking for settings that give students the chance to enjoy the sheer joy and thrill of discovery and the fun of learning. The novelty of these settings for this group of students could potentially provide the stimulus to create interest in these fields.

\section{Attention to Diversity}

Because these academically-talented students in the Young Scholars Program are very likely to eventually attend the University, they represent an ideal population from which to recruit people from underrepresented ethnic groups for the college. The college faculty has demonstrably increased the representation of women, but has shown no progress in expanding racial/ethnic diversity. The virtual absence of qualified minority applicants for faculty positions can be no surprise in light of their conspicuous absence in student populations. Agricultural educators have only recently begun to acknowledge the idea that "it is imperative that every citizen develop a basic understanding of and appreciation for the industry of agriculture" (Birkenholz, 1993, p. iv), much less actually recruit nontraditional students to study agriculture. Agricultural education has traditionally been dedicated to a very specific audience. As recently as 1991, a committee reported to the American Association for Agricultural Education that "nothing special or different has been done in most agricultural education de- 
partments across the nation for recruitment and/or retention of students (graduates or undergraduates) from diverse populations" (Bowen et al., 1991, p. 6). This group also reported that there is a great need to promote sensitivity to issues of diversity because most of these programs do not perceive addressing underrepresentation as a concern. A secondary challenge in this project was convincing the agricultural community that there was good reason to make this outreach effort and to persuade the young scholars that agriculture had relevance in their lives.

To counter the students' existing negative ideas about agriculture, the effort was made to develop a program that moved away from the context of a structured career exploration toward the primary goal of increasing their understanding of the field or agricultural literacy. As very few urban children have had direct experience with agriculture, other than possibly visiting a farm, we were interested in exposing them to multiple science possibilities. "Agriscience" examples demonstrated the tremendous versatility of the field. By diminishing the formality of the usual context of science classes, or even their career exploration experiences, we allowed the students to focus on whatever they found relevant or of personal interest. By involving as many female and nonwhite scientists as possible we made a concerted effort to address the impression that agricultural scientists are only white men. We made sure the students saw people like themselves who actually are part of the college community, because of our understanding that the absence of role models is a crucial deterrent in the sciences. There was, however, no evidence that this made an impression on the scholars, because there was a conspicuous lack of any mention of race/ethnicity of the presenters in their evaluative comments.

\section{Educational Emphasis}

Although recruiting potential students was certainly the motivation for the financial support of the initiative, it was strategically given secondary status in program emphasis. The chances of successful recruiting seemed to be greater if student perceptions of agriculture changed first. The initiative was based on the assumption that if the students could be given a more accurate picture of agricultural science, there was a much better chance they might choose to consider one of the departments as a potential field of study. The intention to provide a scientifically educative experience for the students prompted the incorporation of several proven pedagogical strategies as crucial aspects of the program design:

- Advance organizer - We gained an idea of the existing knowledge of agricultural science and were able to prepare the students for what they could expect from the experience. With the emphasis on agricultural literacy this setting allowed for dissemination of general information to all students.

- Study Guide questions - The students were motivated to interact verbally with the scientists and the scripted questions usually initiated longer conversations that allowed students to raise issues that interested them.

- Cooperative learning-By working in teams the social learning generated greater levels of engagement and involvement. Some of the students that were less comfortable in the setting benefited from the interaction with and encouragement from other students.

- Science/writing activity - The essays written in their study halls on the night after the trip prompted reflection and reinforced what was learned. This exercise was intended to encourage the students to consciously attend to any changes that had taken place in their impressions of agricultural science. 


\section{Field Trips}

Six sites in various college departments were selected and designated to grade levels on the basis of age-related appeal. The locations and a brief description of the students' activities on the excursions are listed below:

- Seventh grade - dairy farm. Students visited the milking parlor, tank room, calf pens, and maternity barn. Demonstrations included reproductive ultrasonography, digestive cannulation, milking, and the parts of the cow.

- Eighth grade-animal science complex. Four groups of students rotated among the sheep, swine, horse, and beef cattle units observing the care, feeding, and housing of the animals. Managers or students gave overviews of each industry.

- Ninth grade-School of Natural Resources. Turf grass management was discussed at the OSU football stadium, marsh ecology was the topic at the Wetland Research Park, and global environmental responsibility was emphasized at a site on campus.

- Tenth grade-horticulture. Touring the campus arboretum, greenhouses, and biocontainment facility was enhanced with exhibits of plants as medicine, photograms, the "sex life" of plants, insects, and a chance to pot an African Basil Plant.

- Eleventh grade-agricultural engineering. The Peace Corps, Agricultural Extension, and agricultural economics combined with agricultural engineering displays of a watershed model, machine safety, remote satellite sensing, food engineering, and machinery.

- Twelfth grade-laboratory science. Ten scientific research groups showed work on aquaculture, sensory evaluation, plant pathology, semen evaluation, plant tissue culture, gas chromatography, dairy processing, food technology, and obesity.

In preparation for the trips, staff from the college office conducted an orientation session that served as an advance organizer. Students were given an overview of the field of agriculture including a video made especially for minority groups and a slide show describing the places they would visit.

\section{Previsit Survey}

Student entry attitudes on disciplinary topics were surveyed with an open-ended instrument, which was summarized by content-coding. Because there was little difference between the classes, the results were combined and are reported for all of the participants. Most of the young scholars $(59 \%)$ said they liked science with the most common reason being that they found it interesting. Only $28 \%$ said they did not like science, and the remainder of the students were neutral. Seventy-four percent of the scholars had visited a farm previously. The same proportion (73\%) admitted that they worry at times about food safety issues. When asked to name their greatest environmental concerns on the global and national level, the six answers that appeared most frequently involved forms of pollution. These surveys provided a sense of student understanding of agriculture and prompted them to think about the subject in preparation for the tours.

To facilitate dialogue between the scholars and the scientists, which had been conspicuously absent in the career explorations held in previous years, we prepared a list of study guide questions. Students were divided into cooperative learning groups to promote social learning. Pizza prizes were awarded to the groups doing the best job of answering these questions. Finally, in their evening study hall after the tours, the scholars participated in an integrated science/writing 
experience where they were asked to write narrative essays abut their trips. This exercise simultaneously reinforced their science lessons, practiced their communication skills, and encouraged critical reflection. Book prizes selected for topical and cultural relevance were awarded at their closing ceremony to the four students in each class who wrote the most outstanding essays. ${ }^{1}$

\section{FROM PRACTICE INTO THEORY}

This project employed an inductive research strategy in which a functional educational innovation was examined after the fact for the generation of insights into educational practices. This approach is typical of action research, which takes a more common-sense approach to grounded inquiry. Knowledge from practical experience rather than established theory is used as the framework (Carr \& Kemmis, 1983). Implications for science education came out of a systematic qualitative analysis based on reflective student essays generated from the science/writing exercise conducted in the study halls after the tours. A total of 521 essays were collected from the 630 students who participated in the tours. While the original papers were returned to each student with a personal comment, photocopies were made for the purpose of evaluation and this research.

The open-ended nature of the assignment to the students dictated the form of analysis that was used to evaluate the papers. Because every student was allowed to write about anything that they chose, it was not possible to tally comments in any numeric fashion. It was, however, quite clear that certain subjects emerged among many of the papers (Glaser \& Strauss, 1967) and these predominant topics indicated a great deal of intersubjective agreement on the part of the students. I looked for the patterns and themes that the students generated. I did not predetermine and impose categories I wanted to examine. This inductive strategy for analysis allowed for a more authentic interpretation of how the students responded to the program (Patton, 1990). Comments in student papers were initially coded according to self-explanatory structural categories: learning, enjoyment, and displeasure. The utility of these categories was apparent from the level of homogeneity within one category and the heterogeneity of the data between these categories (Guba, 1990). Learning was deemed to be of the greatest interest and subsequent sorting of comments within this group led to the emergence of identifiable subsets:

- Content knowledge included the straightforward presentation of facts and the display of new vocabulary, comments about processes, statistics, or numbers. Data tended to be information the students repeated in the way they had heard them and statements tended to sound similar when presented by several students.

- Conceptual understandings were ideas that the students had developed on the basis of what they had seen or heard on the tours. These tended to be statements that demonstrated the students' capacity for flexibly demonstrating knowledge. Remarks on the same topic were expressed differently by each person showing how each had stepped back and thought in their own way. These remarks gave an indication of students grasping and appreciating the overarching significance.

- Changed impressions were comments that referred to testimony involving ideas about agriculture that were no longer the same as they had been before the tour. This category included evidence that students' beliefs about the nature of agriculture has been revised

\footnotetext{
${ }^{1}$ These prizes included: "Blacks in Science," by Ivan van Sertima (Most Scientific Essay); "A Gathering of Old Men," by Earnest Gaines (Most Agricultural Essay); "Jubilee \& How I Wrote Jubilee," by Margaret Walker (Two Best-Written Essays).
} 
on the basis of this experience. These were the new views that indicated a restructuring of the old perspectives or misconceptions they had held about agriculture.

Significant themes became identifiable from this arrangement of quotes made by the participants and it became possible to gain insight into the impressions the tours made on these young people. The prevalence of certain observations was considered an indication that an idea warranted attention in the analysis as did the emphatic nature with which some students made other comments. I made constant validity checks (Bernard, 1988) which appraised the data for consistencies and inconsistencies, considering why students might agree or disagree on specific points. The quotes that have been selected for presentation, in most cases, are representative of the emergent themes within the student essays. The specific choices were often particularly emphatic, thereby making them most valuable for conveying the flavor of the students' responses to the experiences.

\section{STUDENTS' EXPERIENCES}

Giving the students voice through their own writing was an effective way of obtaining authentic information. There was a great deal of positive testimony that would have been unlikely to come out in any public forum among young people. There was also a freedom to make critical comments that might have been stifled out of a sense of impoliteness or fear of casting a bad reflection on the Young Scholars Program. Falk (1983) discusses the intrusive nature of most evaluative research sampling strategies associated with informal educational innovations. These students show signs of "Likert overdose," having been forced to fill out so many evaluation instruments as participants in a model educational program. In the essay format, they were extremely articulate about their reactions to their agriculture visits, providing a tremendous wealth of information as an integral part of their educational activity.

More than half of the participants balanced their critiques highlighting what they appreciated as well as what they disliked. Approximately equal proportions of the remainder gave distinctly favorable or very disapproving views of the tours. Initially, there was some question as to how to interpret the large number of negative statements. Several of their teachers suggested they be ignored as nothing more than "adolescent noise." This suggestion was disregarded out of respect for the fact that the students expressed their honest feelings and the likelihood that these would be useful aspects of both formative and summative evaluation. When the negative reactions were sorted, there were clear patterns within the grade levels that identified specific aspects of each particular tour that were unpopular with large numbers of students. Most often their complaints referred to the animal smells, logistical inconveniences, and the weather on specific days.

The variety of different labels the students used in their essays to refer to the visits are some indication of the effect of the informal structure of these educational experiences. Student essays referred to "trips," "experiences," "expeditions," "tours," "visits," and even "scavenger hunts." Such comments indicate differences in students' responses to the activities. There were also quite a few references to the idea of the trips being "career exploration" in spite of the efforts made to explicitly recontextualize the visits. These appeared in essays from all of the grade levels, but were most prevalent from the older students who had spent several previous summers on campus. Some people indicated that they had a positive impression of the vocational possibilities in the fields they had been exposed to:

This year's career exploration has allowed me to view the field of agriculture in a new and revelational perspective. 
I learned at the career exploration that agriculture is more than just a farm and farm work.

I really had fun learning something new and exploring different fields in agriculture that I rarely knew about.

My trip showed me that there are many other jobs in various fields that are widely ignored.

I liked this subject a lot because you don't have to be one certain thing.

I believe that this career expo was one of the best ones I've been in through these past few years.

Every career exploration that I have attended since I have been in the program disappointed me, but the Agricultural Center fascinated me.

Most of the negative comments fell into thematic patterns that varied on the particular tours. In the seventh and eighth grade the animal smells at the farm predominated. The ninth and tenth graders justifiably complained about their discomfort from the extreme temperatures caused by a summer heat wave. The eleventh and twelfth graders who were unhappy mainly mentioned that they were interested in other career fields and felt they were wasting their time visiting agriculture. Some of the more negative remarks included:

I'm not really interested in agriculture, so therefore the career exploration was very uninteresting and boring.

Maybe I don't like it because I'm not interested in that field of work for a career.

Why do we keep going on these trips to see professions that nobody wants to go into?

This career exploration was a waste of money and time. The world is growing very rapidly in technology and computers. Why were we learning about farming?

Even when they did not enjoy being there, many admitted they had an educational experience:

The field trip was not really fun, but it was educational. That is what is important, Education.

Agriculture is not something I would make a living out of but it was great learning about it.

It was a chance to learn about common things that we never really considered finding out about that affect our daily life.

I learned a lot. I'm not really into agriculture, but I really enjoyed going.

It was education, but a little more than I wanted to know.

In moving these students out of their classrooms, it was possible to provoke their interest in agricultural science. One impact of the informal setting was relayed in comments that reflected their surprise about enjoying the visits:

The agricultural tour did not seem as dull as many people thought it would be. 
I didn't expect to enjoy myself but I did somewhat.

I have to admit I thought I would be bored out of my little mind, but I was truly mistaken because I found the tours very interesting.

I'm not saying that the tour changed my life, but it was informative and most importantly wasn't boring.

Usually I would be bored with something like that, but my attention was kept up.

As an individual who lacks attention span, I really enjoyed the fast pace.

Given the six grade levels, and range of chronological ages among the scholars, it is hardly surprising that there were fundamental differences in what they learned in the science lessons. There was a shift in a tendency to relate content knowledge in a very isolated factual manner among the younger students and the emergence of some evidence of conceptual understanding by making independent broader connections from the older participants. Seventh, eighth, and ninth graders marveled at new vocabulary, facts, and figures:

A female cow is called a heifer and a male cow is called a bull.

I learned that the word farrow means when a pig has a baby and after she has one she is called a sow.

I learned to tell the difference between a Jersey cow and a Holstein cow.

I learned that horseshoes are made of steel and aluminum.

The lawn mower they use to cut it [football turf] costs about $\$ 20,000$.

I did not know that a cow has four stomachs.

They have a machine that milks the cows and the cows give milk two times a day and 365 days a year.

The older students demonstrated their intellectual development and academic maturity by connecting what they saw to broader issues:

The horses eyes are different than ours because when it bends over to eat or drink it can look left and right and look at the same time so it can watch out for predators.

Many farmers don't use pesticides to save money, not because they care about health.

The effects of damaged popcorn could change the quality of the popped kernels.

Natural resources run the world, help the nations, and continue the circle of life and the riches.

After bacteria was destroyed in the milk it became safer and more marketable. 
In rat research I realized how much other animals and human beings could possibly have in common.

It is neither specifically the heat or the grease that makes popcorn pop, but the water in each kernel.

Through advance preparation in written documentation clarifying the background of the visitors and the goals of the program, agricultural scientists were able to orient their presentations appropriately. Specific measures were taken to be sensitive to the particular needs of nonwhite students as recommended by Maestas (1976). These included the efforts to promote conversation and the written feedback on their essays. These were deliberate attempts to give nontraditional students crucial encouragement and a message that they belong (Powell, 1990). The casual atmosphere broke down the usual distance these students felt between themselves and members of the academic community. Some of the young scholars' recognition included comments such as:

They made me feel at home.

When we were rude the people were still polite.

These stations were run by extremely friendly workers with good presentations.

I feel the tour guides were nice and knowledgeable.

I was delighted by the way they accepted the scholars with open arms.

The people on the farm were very friendly and explained things very clearly.

It was a nice thing for the OSU people to do for us, knowing that most people don't want us in their building.

Kunjufu (1986) talks about making education more multicultural, Africentric, and relevant to reach African American students. The scholars validated this by expressing their appreciation for learning:

I learned the soil in Africa is red.

If you visit Africa, their soil is very dry and that only some plants can grow there.

In Africa there is this desert where few people live that has low water and is all grassy.

People studying soil . . . helped people in Africa because the soil was blowing away during storms.

I could show Black Americans that life doesn't stop at the ghetto.

This has excited me to the extent of sharing my knowledge of agriculture with others.

When we came out of the greenhouse, we potted our own African Blue Basil Plants. 
Out of the previously mentioned realization that the scholars might hold fairly negative impressions of agriculture, we explicitly attempted to alter their perceptions of the industry. Without excluding farming from the picture, we expanded the view of agriculture to emphasize the scientific intricacies and to include other unrecognized components of the industry. Clear testimony as to changes in students' conceptions of agricultural science document the success of this strategy:

The science associated with agriculture is more advanced than most people realize.

It contained a lot of educational things which I would never have guessed could be found in the field of agriculture.

I come to find that agriculture does not pertain only to farming but expands to . . . and a quality of the product itself.

Agriculture has a lot more to offer than I first expected.

The most surprising thing I learned . . . is the vast array of occupations available in the field of agriculture.

Usually when I heard the word agriculture I thought of farming but now many other things come to mind.

I never knew agriculture could be so interesting as well as challenging.

After learning about the vast world of agriculture, I found out it isn't all about "Old MacDonald."

I see also that what we may see as a country farmer is really a complex scientist.

Overall, the whole trip was interesting. It made me view agriculture in a different perspective.

Even more validating were the statements that participants were considering collegiate study in agricultural majors as a consequence of the program. The previous failures of multiple efforts to interest students led to the suspicion that this informal approach might be responsible for the apparent success as demonstrated when they said:

This tour really got me to think about majoring in science as well as medicine.

You made me think twice about the career I wish to go in and about the minor I wish to choose.

The stuff I learned was very interesting and I hope to pursue some kind of career in science.

I am really interested in one of these fields. I hope I can speak to someone to learn more about it. It was interesting and almost motivated me to get involved in those fields of study.

Being on these tours made me open my mind about agriculture, I might consider studying in agriculture. 
I am a person that is very interested in science, and I was amazed and satisfied with the quality of each of the labs.

I won't be surprised if I take one of those courses in the future.

\section{EDUCATIONAL IMPLICATIONS}

If we are to begin to have greater success reaching all students in science education, it will be necessary to look for pedagogical innovations specifically suited to reach underserved students. There has long been a perception that science education has little reason to concern itself with social issues, but we must recognize that science does not occur outside of a cultural context and our educational strategies can be reshaped into practices that address members of all ethnic groups. The rigid impersonal style of most university science instruction is not appealing to many students of color. Science presentations can seem excessively formal and unfriendly to people who come from a strong community where human contact is valued. One particular student comment testifies to the impact of the informal structure of the presentations in this program:

The researchers did their part and made the event interesting by not sounding stiff like researchers, but an equal person with wonderful knowledge to share with people that need it.

The chance of continuing support for this type of outreach depends very much on the impression of scientists and administrators. If these people consider their time and money well spent, they might consent to be involved again. With the limited value placed on service activity, especially for the staff members who were so crucial as nontraditional role models in this initiative, multiple efforts were made to reward participation. Of the comments made by the scientists, most spoke positively of their experience:

I think it is a good program to expose all the opportunities that the college can offer students.

I think it is important to expose the participants to what we do.

This was very productive because it is important for students to see minorities in the workplace.

I was impressed with the attentiveness of the students and their interest in agriculture.

The participating scientists seemed to believe in the moral and social value of the project and the potential for its educational significance. They seemed to understand the experimental nature of the endeavor and indicated their feeling of success using this revised approach with the students. There was repeated reference to the "potential" or "impact" that the program could have:

The potential is there to make an impact on many young people.

Usually our visitors are those that are already interested, the Young Scholars visit gave us a chance to talk to an audience of potential students.

If we can have any positive impact, we should continue to try to do so.

It was difficult to know if you've really made an impact, the proof will be in the future. 
Most science education challenges are less pronounced than the idea of "selling" agriculture to urban African American students, but this example can be a lesson for others. These Young Scholars' academic interests and idea of a desirable lifestyle in terms of location and social activity are likely to be very different than anything they associate with agriculture. By inviting the students to the college for casual but deliberate exposure to agricultural science, it was possible to challenge their existing notions and change their perceptions of the field. As Woodson (1933) once said, "It is merely a matter of exercising common sense in approaching people through their environment in order to deal with conditions as they are rather than as you would like to see them or imagine they are." It was not realistic to assume these students were familiar with the topic, so it was crucial to begin by helping them understand it. These students all live in cities and, because their food comes directly from a grocery store, they are unlikely to consider the industry involved in its production. Exhibits were chosen to emphasize the personal relevance of agricultural science. The students reported making personal connections in the majority of the essays.

The relaxation of the context of this educational experience seemed to allow students to interpret the demonstrations in ways that were more meaningful. Since Lankford (1992) has shown that the field-trip format can be a factor in learning retention, we hope that there will be a lasting individual impact on many of the participants. The value of early and extensive exposure to science has been documented by Rowe (1977) as a way of influencing decisions African American students make about science professions, so we also hope that some of them will pursue academic study and consider careers in these fields. Thus, this project addressed both mainline (literacy) and pipeline (career) issues in science education. Rather than accept the idea that science education is a situation where it is only possible to either serve many students in the interest of science literacy or a few students in a prevocational program, we set out to deliberately connect these two roles. This is also an example of a way that science education can make conscious efforts to engage in more inclusive practices. The goal of this project was to modify the curriculum so that, as Atwater (1995) suggests, urban students can become scientifically literate members of American society. We are optimistic that a byproduct of that literacy will be an inclination toward participation. Science education will continue to serve as the pipeline supplying the next generation of scientific and technical workers. If students of color are to be brought into that pipeline in greater numbers, it will be necessary to reshape their early educational experiences. We operated with the idea that science literacy could fill the well that feeds the science pipeline.

\section{REFERENCES}

Arkinstall, M. J. (1977). Organizing school journeys. London: Ward Lock Educational.

Atwater, M. M. (1995). A study of urban middle school students with high and low attitudes toward science. Journal of Research in Science Teaching, 32(6), 665-667.

Bernard, H. R. (1988). Research methods in cultural anthropology. Newbury Park, CA: Sage.

Birkenholz, R. J. (1993). Pilot study of agricultural literacy. Final report on a project funded by the United States Department of Agriculture Cooperative Extension Service.

Bowen, B. E., Gonzales, M., Norland, E., Schumacher, L. G., Vaughn, P., \& Whent, L. (1991). Diversifying the profession-Recruitment, retention, and career enhancement strategies utilized with underrepresented groups. Committee Report for the American Association for Agricultural Education.

Carr, W., \& Kemmis, S. (1983). Becoming critical: Knowing through action research. Victoria, Australia: Deakin University Press.

Catsambis, S. (1995). Gender, race, ethnicity, and science education in the middle grades. Journal of Research in Science Teaching, 32(3), 243-257.

Dierking, L. D., \& Falk, J. H. (1994). Family behavior and learning in informal science settings: A review of the research. Science Education, 78(1), 57-72. 
Falk, J. H. (1983). Time and behavior as predictors of learning. Science Education, 67(2), 267-276.

Falk, J. H., Martin, W. W., \& Balling, J. D. (1978). The novel field-trip phenomenon: Adjustments to novel settings interferes with task learning. Journal of Research in Science Teaching, 15(2), $127-134$.

Glaser, B., \& Strauss, A. (1967). The discovery of grounded theory. Chicago: Aldine.

Guba, E. (1990). The paradigm dialog. Newbury Park, CA: Sage.

Hammerman, D. R., \& Hammerman, W. M. (1973). Teaching in the outdoors. Minneapolis, MN: Burgess Publishing.

hooks, b. (1994). Teaching to transgress. New York: Routledge.

Krepel, W. J., \& DuVall, C. R. (1981). Field trips: A guide for planning and conducting educational experiences. Washington, DC: National Educational Association.

Kunjufu, J. (1986). Countering the conspiracy to destroy black boys. (Vol. III). Chicago: African American Images.

Lankford, M. D. (1992). Successful field trips. Santa Barbara, CA: ABC-CLIO.

Lee, O., Fradd, S. H., \& Sutman, F. X. (1995). Science knowledge and cognitive strategy use among culturally and linguistically diverse students. Journal of Research in Science Teaching, 32(8), $797-816$.

Maestas, S. (1976). Sociocultural factors as a deterrent to students' pursuit of the sciences. In V. L. Melnick \& F. D. Hamilton (Eds.), Minorities in science: The challenge for change in biomedicine. New York: Plenum Press.

National Science Foundation. (1994). Women, minorities, and persons with disabilities in science and engineering: 1994. Arlington, VA: NSF.

Ohio State University Office of Minority Affairs Young Scholars Program. (1995a). Strategic plan 1995-2002. Columbus, OH: The Ohio State University.

Ohio State University Office of Minority Affairs Young Scholars Program. (1995b). 1994 Comprehensive evaluation. Columbus, $\mathrm{OH}$ : The Ohio State University.

Patton, M. Q. (1990). Qualitative evaluation and research methods. Newbury Park, CA: Sage.

Powell, L. (1990). Factors associated with the underrepresentation of African Americans in mathematics and science. Journal of Negro Education, 59(3), 292-299.

Rowe, M. B. (1977). Why don't blacks pick science? The Science Teacher, 44(2), 34-35.

Woodson, C. G. (1933). The mis-education of the Negro. Trenton, NJ: Africa World Press. 